\title{
BARRIERS TO CATARACT SURGICAL UPTAKE IN THE UPPER EAST REGION OF GHANA
}

\author{
"M. E. GYASI ${ }^{1}$, W. M. K. AMOAKU' ${ }^{2}$ AND D.K. ASAMANY ${ }^{3}$ \\ ${ }^{1}$ Presbytarian Hospital Eye Unit, P.O. Box 45, Bawku, Ghana; ${ }^{2}$ Department of Ophthalmology, Uni- \\ versity Hospital, Queen's Medical Centre, Nottingham, NG7 2RD, United Kingdom; ${ }^{3}$ Regional \\ Health Directorate, Bolgatanga, Ghana
}

\begin{abstract}
SUMMARY
Background: The Upper East Region has one of the highest cataract surgical rates in Ghana. Notwithstanding this, cataract blindness is still a major problem.

Aim: To determine patient-related barriers to cataract services in the region and their resolution..

Methods: Focus Group Discussion (FGD) and Indepth interviews were used to explore the opinions of 66 cataract patients resident in the region between July and August 2003. Purposeful sampling was used in selecting 24 patients in the hospital while a Snowball sampling method was employed on 42 respondents resident in the village communities

Results: Average age of the respondents was 67.6 years with equal proportions of males and females (0.9:1). Twelve and fifteen percent of respondents respectively cited fear and lack of escort as barriers to service up-take while $8 \%$ and $9 \%$ pointed to sociocultural beliefs and the fact that they were able to cope satisfactorily with their disability. Only $1.5 \%$ of respondents gave lack of awareness as a barrier with none citing geographical barrier as a problem. Cost of surgery, however, stood out clearly as a very significant barrier with $91 \%$ of respondents attesting to it.

Conclusion: It is concluded that further expansion of outreach services, coupled with a more intensive health education is needed to overcome these barriers.
\end{abstract}

Keywords: Barriers, Ghana, Cataract surgery

\section{INTRODUCTION}

Cataract blindness affects some 105,000 people living in Ghana with about 21,000 new cases occurring every year (estimated population of 21 million) ${ }^{1}$ Management largely centers on the removal of the opacified lens and correcting the resulting hypermetropia with an intraocular lens implant. The procedure is one of the few surgical interventions in which cost benefit analysis has extensively been studied. Two of such studies have compared cataract surgery with no surgery at all. Surgical intervention was found to have greater monetary benefits than costs, even without taking into account intangible benefits like increased sight. ${ }^{2,3}$ Tuominen et al (1988) showed further that the insertion of an intraocular lens implant gave a higher net present benefit. ${ }^{3}$ Despite these obvious benefits of cataract surgery, cataract remains the leading cause of blindness in Ghana as a result of a number of barriers between patients and the available services. These barriers have traditionally been classified into institution-related (service provision) and patient-related barriers. This study looked at the latter in an environment where the former is largely controlled.

\section{METHOD}

Qualitative research methods were used to explore the opinions of 66 cataract patients residing in the Upper East Region of Ghana between July 2003 and August 2003. Twenty four of the respondents were cataract patients who had come to the Bawku Hospital for surgery while the remaining 42 were cataract-blind patients in villages in the region.

\section{Sampling Methods}

Purposive sampling was used in selecting the hospital respondents. For respondents in the villages, a Snowball sampling strategy was used by first identifying an index village where at least a cataract blind person lived. The knowledge of the local people was used to identify other communities with cataract blind persons. This continued until the desired number of respondents was identified.

\section{Data Collection}

Focus Group Discussion complemented with Indepth Interview was carried out to explore the same set of issues. This was done to allow triangulation of findings. In each case, themes were extensively discussed until a point of theoretical saturation was reached. As new themes emerged, the template of open-ended questions was modified to probe these further. Ranking was done on extracted themes by developing a rating scale of 1 to 10 and converting the results into percentages. To evaluate potential geographical barriers, the regional Geographical Information System (GIS) software at

* Corresponding Author

mikegyasi@yahoo.co.uk 
the Ghana Health Service biostatistics office was used to compute the actual distances by road from the farthest village communities to the nearest clinic/hospital where cataract surgical services are offered.

\section{Data Analysis}

The data was analyzed using a Thematic Framework approach to extract major themes and sub-themes. Quantitative outcomes were analyzed using simple hand-held calculators.

\section{Ethical Issues}

Informed consent was obtained from each participant through the signing or thumb-printing of a prepared consent form. Where the patient could not thumb-print nor sign, this was done by a close relative. The protocol was approved by the Bawku Hospital ethical committee and accepted by the London School of Hygiene and Tropical Medicine.

\section{RESULTS}

\section{Demographic Data}

Over $80 \%$ of the respondents were above 60 years with equal proportions of males and females (ratio $=0.9: 1$ ). Table 1 shows the distribution of respondents in the various groups.

Table 1 Demographic data

\begin{tabular}{lllll}
\hline Groups & Number & Av. Age & Sex & \\
& & (years) & M & F \\
\hline FGD 1 & 8 & 64 & 4 & 4 \\
FGD 2 & 8 & 68 & 5 & 3 \\
FGD 3 & 8 & 72 & 4 & 4 \\
Village & 42 & 67 & 18 & 24 \\
Total & 66 & 67.6 & 31 & 35 \\
\hline
\end{tabular}

\section{Rated Responses to Identified Barriers}

Cost was identified by $91 \%$ of respondents as the most important barrier to the uptake of cataract surgery.

Table 2 Rated responses to identified barriers

\begin{tabular}{llll}
\hline Barriers & \multicolumn{2}{l}{ Responses } & \% Yes \\
& Yes & No & \\
\hline Cost & 60 & 6 & 90.9 \\
Lack of awareness & 1 & 65 & 1.5 \\
Fear & 8 & 58 & 12.5 \\
Lack of Escort & 10 & 56 & 15.2 \\
Distance & 0 & 66 & 0 \\
No perceived need & 6 & 60 & 9.1 \\
Socio-cultural beliefs & 5 & 61 & 7.6 \\
\hline
\end{tabular}

This was especially so with regards to direct cost which included cost of the operation, drugs, transport and feeding. Lack of escort service was found to be the second most important barrier (15.2\%) and this was attributed mainly to lack of accommodation for the escorts who usually had to come from the villages. Table 2 shows other factors including fear (12.5\%), patients' ability to cope with disability (9.1\%), sociocultural beliefs (7.6\%) and lack of awareness (1.5\%).

Table 3 Sponsors of Cataract Surgery

\begin{tabular}{lll}
\hline Sponsors & No & $\%$ \\
\hline Self & 5 & 20.8 \\
Children & 12 & 50.0 \\
Spouse & 3 & 12.5 \\
Other relatives & 1 & 4.2 \\
NGO & 2 & 8.3 \\
Hospital & 1 & 4.2 \\
TOTAL & 24 & 100 \\
\hline
\end{tabular}

Table 4 GIS-computed distances of cataract service centers

\begin{tabular}{|l|l|l|l|}
\hline $\begin{array}{l}\text { District } \\
\text { (Hospital) }\end{array}$ & $\begin{array}{l}\text { Farthest } \\
\text { Community }\end{array}$ & Location & $\begin{array}{l}\text { Distance } \\
\text { (km) }\end{array}$ \\
\hline $\begin{array}{l}\text { Kassena Nan- } \\
\text { kana } \\
\text { (Navrongo) }\end{array}$ & $\begin{array}{l}\text { Buluri Tin- } \\
\text { dan }\end{array}$ & West & 40.0 \\
\hline $\begin{array}{l}\text { Builsa (San- } \\
\text { dema) }\end{array}$ & $\begin{array}{l}\text { Gbeden } \\
\text { Bilisi }\end{array}$ & South & 45.6 \\
\hline Bongo(Bongo) & Soe & East & 15 \\
\hline $\begin{array}{l}\text { Bolgatanga } \\
\text { (Bolgatanga) }\end{array}$ & Tula & South & 44.8 \\
\hline $\begin{array}{l}\text { Bawku West } \\
\text { (Zebilla)* }\end{array}$ & Yiboni & South & 57.8 \\
\hline $\begin{array}{l}\text { Bawku } \\
\text { East(Bawku) } \\
\text { Garu-Timpani } \\
\text { (Garu)* }\end{array}$ & $\begin{array}{l}\text { Buluntanga } \\
\text { Takori }\end{array}$ & $\begin{array}{l}\text { West } \\
\text { South }\end{array}$ & 34.3 \\
\hline
\end{tabular}

*New centres set up following findings of the study

Among the respondents at the hospital, the cost of surgery was either borne directly by the patients or family members with the remaining paid for by the hospital as part of its free treatment policy, or with funds from Non-governmental Organizations operating in the region (Table 3).

\section{Service Accessibility}

No respondent cited distance from service location as a barrier. Evaluation of distances from communities to hospitals where cataract surgical services are delivered is presented in Table 4. 


\section{DISCUSSION}

Blindness from cataract is curable and the facilities to effect such treatment in the Upper East region are readily available. Patients' use of such services, like all other health care services is influenced by a number of factors that can conveniently be classified in ABC format as: Lack of Awareness, Bad Surgery, Cost of surgery and Cultural beliefs, Distance from service, lack of Escort and Fear. These factors constitute a major barrier between cataract patients and service providers resulting in low up-take in the presence of adequate service availability. In Nepal, ${ }^{4}$ uptake of cataract services by patients is estimated at $46 \%$ while in Malawi ${ }^{5}$ it is merely $8 \%$. In India, uptake ranges from $14-34 \%{ }^{6}$ While these barriers appear to affect both sexes, some studies have reported a more female preponderance. ${ }^{\mathbf{6}, 7}$ This feature was however not evaluated in our current study.

In this study cost was found to be the most important barrier to the uptake of cataract surgery in the region. This is in spite of the fact that the cost of cataract operation in the Upper East region is among the lowest in the country (400,000 cedis). It is however noteworthy that the family system (spouse, children, and other family members) paid for 66.7 percent (Table 3 ) of the patients and this we consider very significant in a region where $88.3 \%$ of the population is below the poverty line. $^{8}$

Positive correlation has been reported between cost reduction and uptake of cataract services in some situations. In an Indian study a reduction in the cost of surgery and provision of transport expenses translated into a significant increase in cataract surgical acceptance. ${ }^{9}$ While it has not been possible to further reduce the fee for cataract operation, it is hoped that with the introduction of the National Health Insurance Scheme, this major barrier would soon be overcome.

Lack of accommodation for the escorts who usually have to come from the villages had been previously identified at the Bawku hospital and a hostel built for the purpose. Unfortunately, however, the rent of 30,000 cedis per night appears to be beyond the reach of these attendants making escort a problematic issue (15.2\%). With the shortage of nurses and ward assistants, it has not been possible to provide full service to patients without some support from relatives. This is especially so in the areas of feeding where currently relatives have to procure their own food from outside. Probably it is time this issue was looked at again in line with practice in other hospitals, where in-house catering services are provided. Rents paid by cataract escorts also require downward revision at the expense of pri- vate lodgers who currently pay the same amount as the escorts in using the hostel facility.

Fear appears to be a major barrier in the region (Table 2). Contrary to findings in other studies, however, most patients expressed fear of the hospital environment, staff and loss of pride and dignity rather than that of cataract surgery. This was not surprising as high quality cataract services have been in the region for nearly thirty years. In addition to this is the role of 'pseudophakic motivators' who have been used over the years to attract more patients to come for surgery. Notwithstanding all these attributes, fear of the unknown appears to have played a major role in deciding on cataract surgery. In a study in Tanzania, it was reported that fear of the city, where to stay, what is going to happen when left alone in the hospital and similar fears far outweighed the perceived advantages of restored sight, among cataract patients. ${ }^{10}$

It is equally not surprising that some of the respondents (in the villages) did not see cataract surgery as a necessity. These findings are consistent with others which show that the mere presence and guarantee of eye care services do not necessarily translate into increased service up-take even if these are provided free of charge. ${ }^{11,12}$ In a study in rural India, only $7 \%$ of people identified with eye problems in communities situated only $5 \mathrm{~km}$ from an on-going free eye camp actually attended the camp. ${ }^{13}$ While some of these can be attributed to patients' adaptation and the general cultural acceptance of blindness as an inevitable part of the ageing process, the other potential reasons could be the 'hidden cost' of cataract surgery which includes loss of work for the patient and escorts, living expenses, transportation etc. In Nepal, these non-surgical costs alone have been estimated to be one-fifth of the annual income of a rural patient. ${ }^{14}$

The very high level of awareness amongst respondents and the absence of any references to geographical barriers (Table 2) were unexpected. Our evaluation of the current locations of outreach centers from the communities show that most cataract patients can access services within an average distance of $39 \mathrm{~km}$ or a travelling time of some 40 minutes (Table 4). Our findings, however, also showed an uneven distribution of the outreach centres. Since the completion of this study, two more centres have been set up in the Bawku West district (Zebilla Hospital) and the Garu Health Centre in the Garu-Timpani district. This should reduce the mean accessibility distance further. 


\section{CONCLUSION}

Poverty, lack of escorts and fear appear to be major factors preventing the attainment of higher cataract surgical uptake in the Upper East region. While some solution to the lack of funds appear to be in sight with the commencement of the National Health Insurance Scheme, effective community-oriented eye health education and further expansion of the outreach programme are being undertaken to overcome the other barriers. The most critical of these, in our view is the service expansion as it directly reduces the need for escort and enhances communication between patients and service thus reducing barriers like fear, cultural and personal beliefs. Other effective measures being implemented include differential pricing system which ensures that the poor can receive free surgery even if they have no money, increased inter-sectoral collaboration with NGOs and corporate organizations, implementation of cost containment policies through local production of essential inputs and efficient use of theatre time. With the implementation of the National Vision 2020 Action Plan, we hope that some of the achievements of the Bawku Eye Care Programme can be duplicated in other regions.

\section{ACKNOWLEDGEMENT}

Sincere thanks to Professor Allen Foster of the International Centre for Eye Health, London School of Hygiene and Tropical Medicine, for supervising this work.

\section{REFERENCES}

1. Ghana Vision 2020, the Right to Sight: National Framework for Action 2002-2006. Feb 2002: 9

2. Bernth-Petersen P. Outcome of cataract surgery: socio-economic aspects. Acta Ophthalmol 1982; 60:461-468
3. Tuominen R, Immonen I. economic evaluation of cataract surgery: a comparison between IOL and non IOL Techniques. Acta Ophthalmol 1988; 66:577-581 4. Snelligen P, Shrestha et al. Socio-economic barriers to cataract surgery in Nepal: the South Asian cataract management study. BJO 1998; 82:1424-1428

5. Courtright S, Kanjaloti S, Lewallen S. Barriers to acceptance of cataract surgery among patients presenting to district hospital in rural Malawi. Trop and Geogra Med 1995; 47:15-18

6. Brilliant GE et al. The operational research group; social determinants of cataract surgery utilization in South India. Arch Ophthalmol 1991;109:584-89

7. Aditi S. Barriers to the uptake of cataract surgery for women in urban Cape Town. J Comm Eye Health 2005; 18:80

8. Ghana Poverty Reduction Strategy 2002-2004, An agenda for growth and prosperity; 2002. p10.

9. Ellwein LP, Lepkowski JM, Thulasiraj RD, Brilliant GE, the operations research group. The cost effectiveness of strategies to reduce barriers to cataract surgery. Int Ophthalmol 1991; 15:175-81.

10. Ingrid Cox. The patient view: how can we improve patient care? J Comm Eye Health 2002;15:3-4

11. Fletcher AE, Donoghue M, Devavaram J, Thulasiraj $\mathrm{RD}$, Scott S, Abdalla $\mathrm{M}$ et al.. Low uptake of eye services in rural India: A challenge for programme of blindness prevention. Arch Ophthalmol 1999; 117:1393-9

12. Brilliant GE, Lepkowski JM, Zurita B, Thulasiraj RD. Social determinants of cataract surgery utilization in South India. Arch Ophthalmol 1991; 109:584-9

13. Donogue M. People who don't use eye services: 'Making the invisible visible' $J$ Comm Eye Health 1999; $12: 36-8$

14. Lewallen S, Courtright P. Recognising and reducing barriers to cataract surgery. J Comm Eye Health 2000; $13: 20-22$ 